\title{
INVOLVING RENEWABLE ENERGY SOURCES IN GENERATING PROCESS: EXAMPLE OF KAZAKHSTAN
}

\author{
Vladislav Zavadskiy ${ }^{1}$, Gita Revalde ${ }^{2}$ \\ ${ }^{1}$ Almaty University of Power Engineering and Telecommunication, Kazakhstan; \\ ${ }^{2}$ Riga Technical University, Latvia \\ vladislav.zavadskiy@gmail.com, gita.revalde@rtu.lv
}

\begin{abstract}
This paper presents a common approach for involving renewable energy sources and unit commitment problem solving in a dispersed power system on the example of Kazakhstan as a factor of the energy sector sustainable development. The methodology includes analyzing of the impact of the regional and global energy trends, legislation and the potential for renewable energy sources. The numerical results show the possibility of solving the problem of unit commitment with renewables with the least operating costs and with the most optimal renewable energy source type in the region. Also, the possibilities of autonomous operation of a part of the dispersed power system with a certain combination of renewable energy sources and electric power storage and covering the electricity deficit from the renewables instead of commissioning of traditional energy sources are shown. We show that solving the problem of electricity deficit in the region with the help of renewable energy, sustainable development of the energy system can be ensured and the impact on the environment can be minimized.
\end{abstract}

Keywords: renewable energy sources, unit commitment, rural regions, global energy trends.

\section{Introduction}

Currently, Kazakhstan is working on the introduction of renewable energy sources (RES) in generation, but there are no studies that would cover the problem of unit commitment (UC) with RES. $\mathrm{UC}$ is a large family of mathematical optimization problems, where the production of a set of electrical generators is coordinated in order to achieve some common target, usually either match the energy demand at minimum cost or maximize revenues from energy production. Quite a lot of works are presented to solve the problem of the unit commitment (e.g., B.Saravanan et al [1] and J.Fossati [2]), however, they are often focused on specific cases and do not provide a general methodology for solving the problem. On the example of Kazakhstan, the solution of this problem is generally considered for the first time in our work.

To the moment, there was no general approach and analysis of the problem of UC with RES in Kazakhstan, which could include a comprehensive analysis of the impact factors on the development of RES in Kazakhstan. The approach has not been worked out and there are no studies of the effect of connecting large RES power plants on the existing generation. Also, there are no specific examples of the use of modelling the work of different types of RES with the electric grid. In addition, there is a lack of research works that would solve the problem of UC, modelling the processes based on a real working dispersed networks. In this work, the simulation of the joint operation of RES to solve the UC problem will be performed. Proceeding from the foregoing, the proposed work is relevant and important from scientific and practical point of view.

In the presented paper the following goal will be set to prove that by solving the unit commitment problem in a dispersed power system (what is the power system of Kazakhstan with a large number of rural regions) with RES, it is possible to cover the shortage of power generation capacities by increasing the share of RES in generating electricity instead of building traditional power facilities. Also, a general approach will be proposed for the UC problem solving in a dispersed power system involving RES on the example of Kazakhstan to fill the shortage of generating capacity and more fully use the potential of RES.

\section{Materials and methods}

Nowadays, the main feature of the process of electricity production and consumption according to its nature is that the produced electrical energy should be used immediately. As a result, to ensure the stable operation of the power system with the specified parameters, it is necessary to build intersystem power lines and observe certain operating modes of electric power generators. This problem can be considered as a special case of the unit commitment problem. The UC problem is defined as an optimization problem used to determine the operation schedule of the generating units at every hour 
interval with varying loads under different constraints and environments [1;2]. Unit commitment problem with the renewables has some features. The most significant is that the produced energy from the renewables is not stable and cannot be regulated in a wide range. Also, usually by the governmental laws the "green" energy from the renewables has the priority of connecting to the electrical grid. Kazakhstan adopted such law. Dispersed power system also imposes some features on the UC problem. The proposed methodology of the UC problem solution in such conditions consists of the following steps:

1. identification of the impact factors on the development and implementation of RES;

2. initial data analysing and selection of the network part for modelling;

3. setting the goal of the commissioning of the new renewable energy capacities and analysing its availability and the profile of the electrical power output from RES;

4. mathematical methods and software selection;

5. getting all required information for performing modelling and solving the UC problem;

6. optimal combination of the RES search and storage facilities capacity selection;

7. performing the UC simulation with different constraints and getting the results;

8. return to the previous steps and re-execute them with new data, if necessary;

9. conclusions and recommendations.

For the UC problem solution and network simulation the MATPOWER and MOST packages, working in the MATLAB environment with a GUROBI solver, were used. Initially it was developed by Ray Zimmerman, Carlos E. Murillo-Sanchez and Deqiang Gan from the Power Systems Engineering Research Center (PSERC) at Cornell University under Roberts J.Thomas with significant contributions from Daniel Munoz-Alvarez and Alberto J. Lamadrid [3; 4]. In this work the method is further developed for the modeling case of the Kazakhstan's electrical network.

We applied the following conditions and assumptions for the chosen network simulation:

- two days were simulated and considered: in summer (22.06.2014) and in winter (22.12.2014);

- wind and solar generation were simulated, both separately and together;

- only active power was considered;

- installed renewable capacity is connected to the bus of the load as well as a storage unit;

- on the basis of the law on support of renewable energy sources for the RES energy sources will be set zero power generation costs [5];

- thermal stations in the simulated system belong to the same owner, and use the same fuel, so economically generation parameters are assumed equal for all generation units, except startup costs [6];

- older aggregates require large expenditure on the process of starting and stopping;

- installation costs of the RES power plants, as well as economic feasibility was considered.

For the share of each type of the RES in daily generation, the average value for two periods (summer and winter) was taken.

To simulate the process of UC with combined production of solar and wind energy, it is necessary to find the optimal fraction of the generation of solar and wind generation. The solution of this problem can be represented as a solution to the problem of nonlinear optimization (NLP). There are many mathematical methods for solving such problems. In our work, we use the Generalized Reduced Gradient Method (GRG) that according to the studies [7] is one of the most suitable methods. The basic idea of the GRG method can be explained as linearizing the non-linear objective and constraint functions at a local solution with Taylor expansion equation. Then, the concept of the reduced gradient method is employed, which divides the variable set into two subsets of basic and non-basic variable and the concept of implicit variable elimination to express the basic variable by the non-basic variable. Finally, the constraints are eliminated, and the variable space is deduced to only non-basic variables. The processes repeat again until they fulfill the optimal conditions. According to the results of calculations, in order to achieve the installed capacity of the combined installation of a solar and wind power plant in $100 \%$, the share of each type of energy should be $100 \%$. This means that, say, to obtain a capacity of $100 \mathrm{MW}$ from wind and sun at the same time, the installed capacity of $100 \mathrm{MW}$ of both a solar power plant and a wind power station is needed. 
For the modelling of the unit commitment problem solution with the renewable energy sources in a dispersed power system the western part of the Kazakhstan's power system has been chosen (Figure 1) [8].

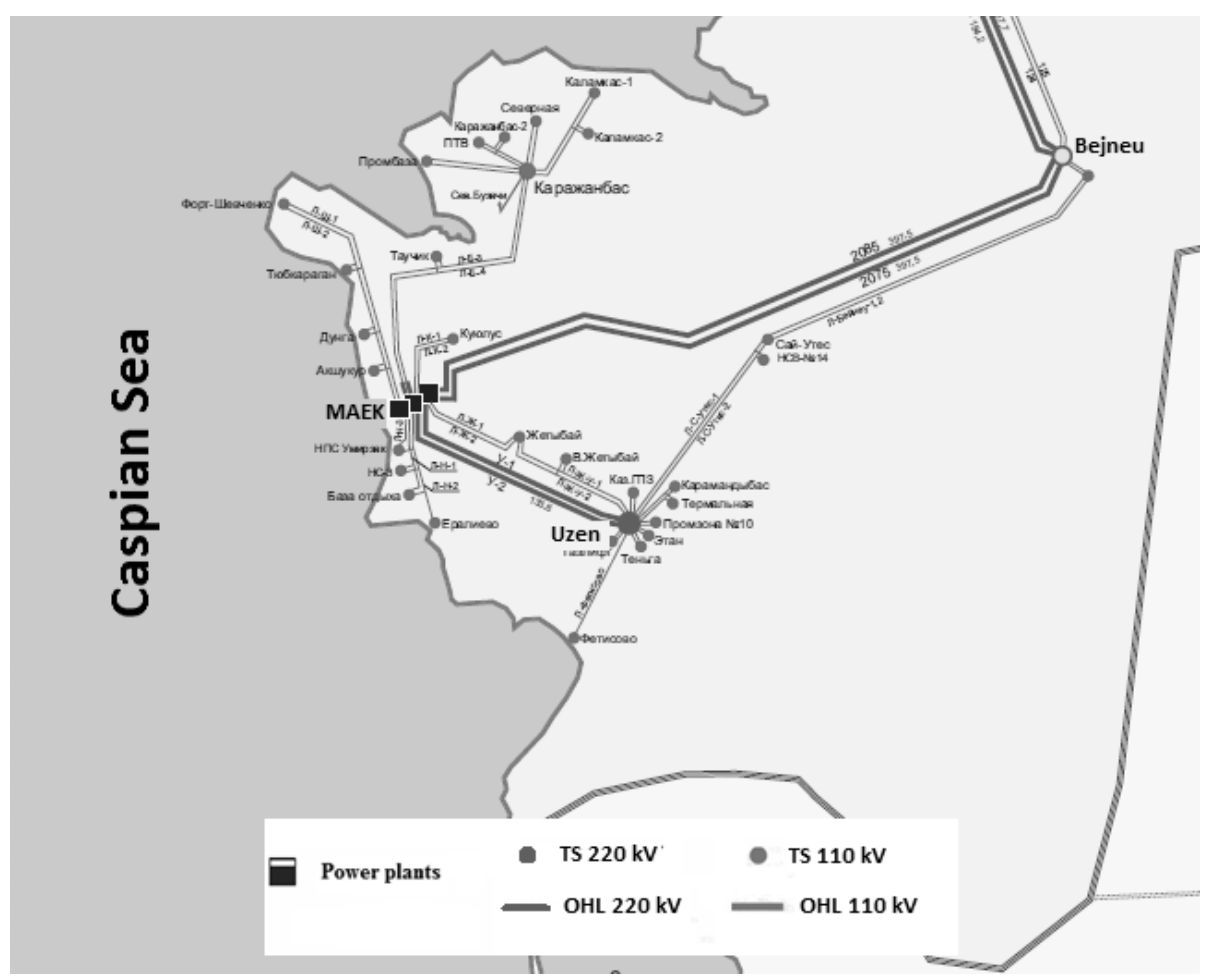

Fig. 1. Western part of power grid of Kazakhstan

Because of the significant lack of the generation capacities, this region is ideal for installing renewable energy sources production facilities. Especially in this region, there is a good potential for them.

To simulate the UC with RES and to test the possibility of replacing the newly installed generating capacity with the RES capacity, the RES of $250 \mathrm{MW}$ installed power facilities was modeled. Also, to test the possibility of covering the electricity deficit in the western zone, the installation of 297 MW of RES power capacity as well as the total power of 547 MW was modeled with the corresponding load values.

For the UC problem simulation and its solving all required data should be inserted in the MOST tool program package. The data needed for the problem are not typically created directly, but rather assembled from numerous other files or data structures [9]. According to the above methodology, it is necessary to analyse the factors affecting the development and integration of RES in the network, as indicated.

Energy sector of Kazakhstan has been developed decades as a part of the Soviet Union's energy sector. Nowadays, as an independent state, Kazakhstan is trying to follow international trends of the energy sector development. To make the reliable forecast of the Kazakhstan energy sector's future structure and to use the proposed method, it is important to look at the global processes in the world's energy sector development and at the forecasts provided by the countries - members of the Eurasian Economic Union (EAEU).

\section{Results and discussion}

\section{World energy trends and energy production structure forecast}

The key index for any energy forecast is the energy demand, which depends on the dynamic of the population level, but not only. The economic situation, energy consumption per capita and energy intensity also are important factors. The increase in energy consumption per capita can be seen as a key indicator of the quality of life and the result of the economic development of the world. Energy intensity of GDP mostly characterized the progress of technological development. So, it is seen that three key indicators should be considered. According the last UN forecast in the year 2040 the world 
population should reach 9.1 billion people (Figure 2) [10]. By this time, the demographic transition from high to low birth rates will basically end.

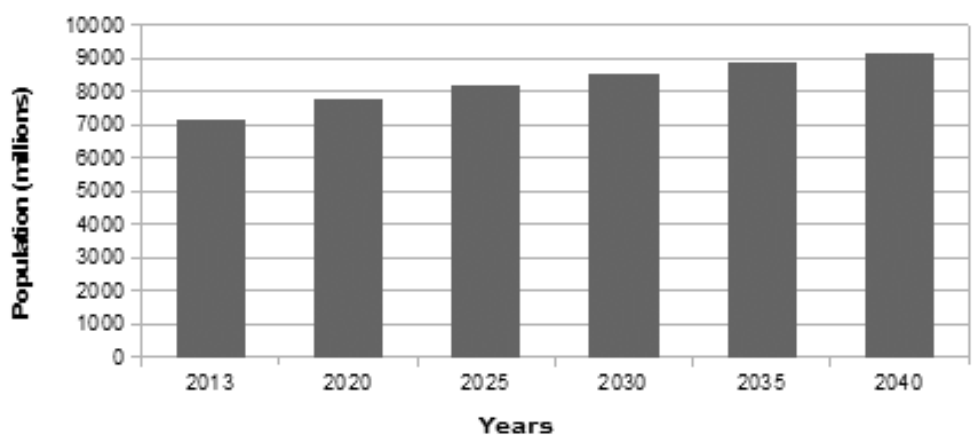

Fig. 2. World population growth forecast

Technology development will undoubtedly have an impact on the energy sector. The most topical problem of the actual energy sector is the energy saving problem. This problem has both economic and environmental components as a driver for innovations. A lot of forecasts are based on the assumption that in the nearest future there will be no technological revolution in the energy sector, but some technological breakthroughs are expected. Such scenario is often called as a basic. It is expecting the decrease in the energy intensity of GDP almost 1.5 times by 2040 (Figure 3) [11].

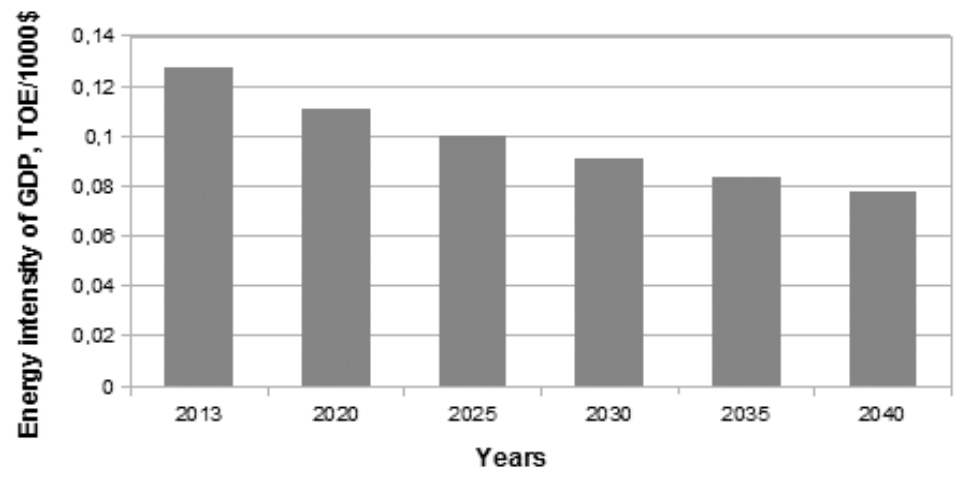

Fig.3. Dynamic of energy intensity of GDP

This factor works to reduce the energy consumption in the world, but the population growth and the growth of energy consumption per capita (Figure 4) as a result will lead to an overall increase in the energy consumption [11].

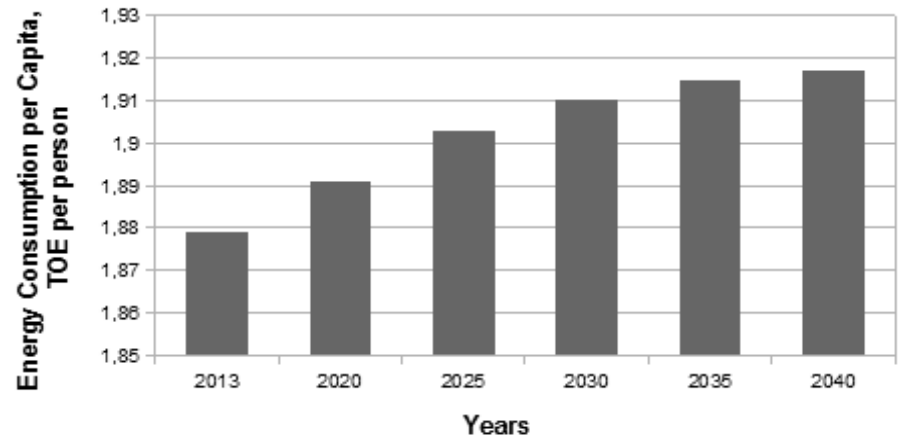

Fig. 4. Dynamic of energy consumption per capita

Energy consumption per capita is a key factor of the life quality and the growth of the index from $1.88 \mathrm{TOE}$ per person to 1.92 is expected.

Kazakhstan was one of the founders of the Eurasian Economic Union (EAEU), which was started in 2014 [12]. The EAEU provides for free movement of goods, services, capital and labor. The common electricity market will be created by 2019 in the EAEU [13]. Availability of the natural resources in the 
region will be reflected in the structure of the primary energy consumption. Natural gas looks like the most demanded source in the region. Power generation structure forecast reflects the global tendencies. The share of the renewable energy sources will be significantly increased by 2040 (Figure 5) [12].

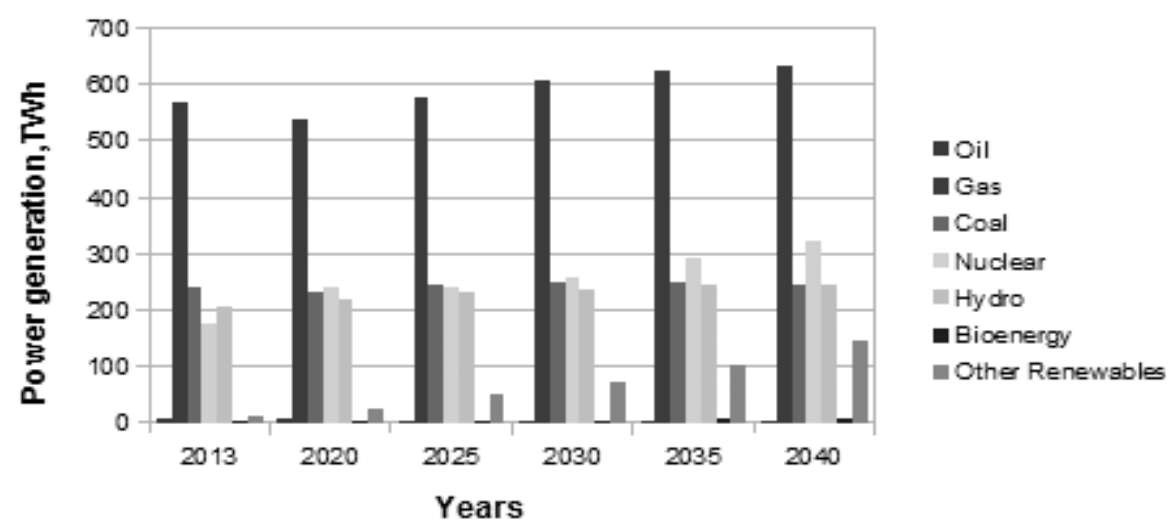

Fig. 5. Energy sector production structure in EAEU

\section{Kazakhstan's energy sector current structure and future development forecast}

Energy sector of the Republic Kazakhstan was formed as a part of the common energy sector of the Soviet Union, of which Kazakhstan was until 1991. After Kazakhstan gained independence, the country's economy was based on the development of energy-intensive industries, although their share fell slightly. The operational control of the United Electrical System (UES) of Kazakhstan is executed by the Central Dispatch Administration (CDA) of UES Kazakhstan as a part of "KEGOC".

The analysis of the dynamics of the production of electricity in Kazakhstan for the period from 2000 to 2015 leads to the conclusion that there is positive dynamics in the industry, the production and consumption of electricity is increasing (Figure 6) [13].

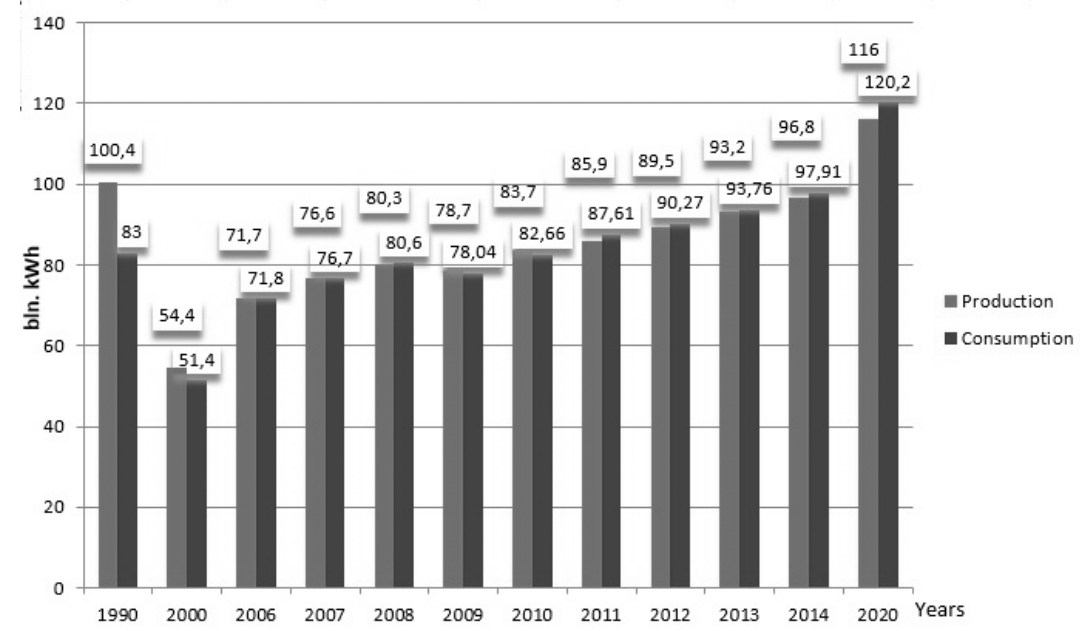

Fig. 6. Dynamics of production and consumption of electricity in the Republic of Kazakhstan during 1990-2020

Today, the installed capacity of power plants in Kazakhstan is 18.992 GW [15], which is comparable with those of the countries such as Switzerland (17,600 thousand MW [16], the Netherlands (15,000 thousand MW [17], Turkey (21,000 thousand MW [18]). Annual electricity production is $86200 \mathrm{GWh}$ [14]. Around $40 \%$ of the installed capacity of the power units is about of 500 and $300 \mathrm{MW}$ and the thermal power capacity reaches 4,000 MW. The overwhelming part (85\%) of electricity produced by burning Kazakhstan's relatively cheap local coal, about $11 \%$ provide hydroelectric power (Figure 7). 


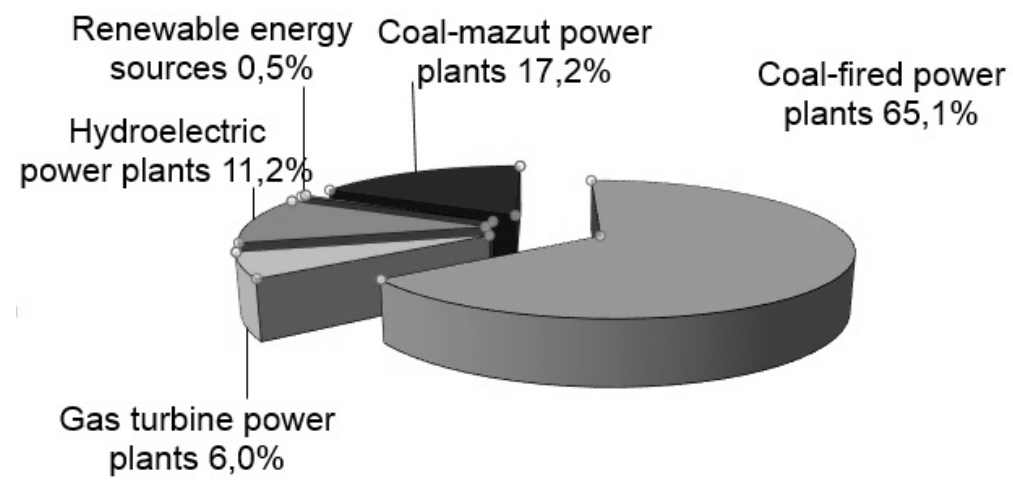

Fig. 7. Structure of installed capacity of power plants in Kazakhstan

\section{Renewable energy sources and their perspectives in Kazakhstan}

Different experts and researches give different values, but undoubtedly the potential of renewable energy resources (wind, solar, hydropower and biomass energy) in Kazakhstan is significant (Table 1) [19]. For example, only the potential of wind power can cover the present demand in electricity by 10 20 times! However, unfortunately, except the part of hydropower, these resources have not been widely used up to the present time.

Table 1

Potential of renewable energy resources in Kazakhstan

\begin{tabular}{|c|c|c|}
\hline Type & Value & Unit \\
\hline Wind & $929-1820$ & billion $\mathrm{kWh}$ per year \\
\hline Solar & 2.5 & billion $\mathrm{kWh}$ per year \\
\hline Biomass energy & 35 & billion $\mathrm{kWh}$ per year \\
\hline Small hydro & 7.5 & billion $\mathrm{kWh}$ per year \\
\hline
\end{tabular}

Analyzing the share of the potential of renewable energy sources (Figure 8), it can be concluded that the most promising are wind and biomass energy.

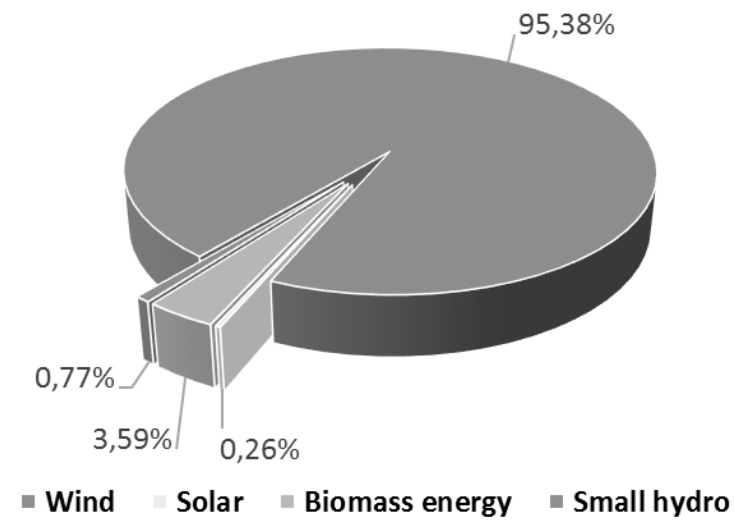

Fig. 8. Shares of renewable energy sources potential in Kazakhstan

However, the widespread use of bioenergy is still limited to the inability to involve big territories of land for special crops, as well as the underdeveloped infrastructure and complicated process of the biofuel production. Undoubtedly, in the future, the use of this type of energy will solve both the problems of power generation and some environmental problems, primarily related to waste disposal. Using the energy of small rivers is also not possible on the entire territory of Kazakhstan mainly due to uneven distribution of water resources. Accessibility in most parts of Kazakhstan and the relative simplicity of installations for generating electricity allows us to consider the sun and wind the most promising renewable sources of electricity at the current moment, especially in rural areas. 


\section{The results of unit commitment problem for the renewable energy sources in Kazakhstan}

The results of the solution of the unit commitment problem for the possibility of replacing generation with the help of RES for Kazakhstan are represented in Table 2. For modelling the power system the western part of the Kazakhstan's power system, as indicated in Fig.1, was used. The possibility of replacing generation with the help of RES was analysed on the basis of the following condition: the same generator did not work for two periods. Maximum values of the excess or deficit of electrical energy were analysed for two periods.

Table 2

Simulation results summery for both periods

\begin{tabular}{|c|c|c|c|c|c|c|c|}
\hline \multirow{3}{*}{$\begin{array}{l}\text { Simulation case } \\
\text { (RES type; } \\
\text { RES power, MW; } \\
\text { Storage capacity, } \\
\text { MW; } \\
\text { Load, region. }\end{array}$} & \multirow{3}{*}{$\begin{array}{c}\text { Average \% } \\
\text { of RES } \\
\text { generation } \\
\text { for two } \\
\text { periods }\end{array}$} & $\begin{array}{c}\text { Max } \\
\text { (Excess } \\
(-)), \\
\text { MW }\end{array}$ & $\begin{array}{c}\text { Max } \\
\text { (Deficit } \\
(+)) \\
\text { MW }\end{array}$ & $\begin{array}{c}\text { Max } \\
(\text { Excess } \\
(-)), \\
\text { MW }\end{array}$ & $\begin{array}{c}\text { Max } \\
\text { (Deficit } \\
(+)), \\
\text { MW }\end{array}$ & \multicolumn{2}{|c|}{$\begin{array}{c}\text { Gen \#, NOT in } \\
\text { operation } \\
\text { during two } \\
\text { periods }\end{array}$} \\
\hline & & \multicolumn{2}{|c|}{ Without } & \multicolumn{2}{|c|}{ With } & Without & With \\
\hline & & \multicolumn{6}{|c|}{ storage unit } \\
\hline $\begin{array}{c}\text { Wind, 250, 269, } \\
\text { Mangistau }\end{array}$ & 18.79 & -22.25 & 0.00 & 0.00 & 0.00 & 0 & 2 \\
\hline $\begin{array}{l}\text { Solar, 250, 214, } \\
\text { Mangistau }\end{array}$ & 5.90 & -42.50 & 0.00 & 0.00 & 0.00 & 0 & 0 \\
\hline $\begin{array}{l}\text { Aggregated, 250, } \\
\text { 299, Mangistau }\end{array}$ & 24.72 & -36.00 & 0.00 & 0.00 & 0.00 & 0 & 2 \\
\hline $\begin{array}{l}\text { Wind, } 297,319, \\
\text { West }\end{array}$ & 14.76 & -26.59 & 0.01 & 0.00 & 0.00 & 0 & 0 \\
\hline $\begin{array}{l}\text { Solar, 297, 255, } \\
\text { West }\end{array}$ & 4.49 & -4.87 & 0.00 & 0.00 & 0.00 & 0 & 0 \\
\hline $\begin{array}{c}\text { Aggregated, 297, } \\
\text { 356, West }\end{array}$ & 19.26 & -8.46 & 0.01 & 0.00 & 0.00 & 0 & 0 \\
\hline $\begin{array}{l}\text { Wind, 547, 588, } \\
\text { West }\end{array}$ & 27.19 & -18.28 & 0.00 & 0.00 & 0.00 & 0 & 0 \\
\hline $\begin{array}{l}\text { Solar, 547, 469, } \\
\text { West }\end{array}$ & 8.27 & -8.12 & 0.01 & 0.00 & 0.00 & 0 & 0 \\
\hline $\begin{array}{c}\text { Aggregated, 547, } \\
655, \text { West }\end{array}$ & 35.28 & -73.02 & 0.00 & -4.75 & 0.00 & 0 & 0 \\
\hline
\end{tabular}

From the results of the calculations shown in the Table 2, it is clear that, if the current load profile remains unchanged, the $250 \mathrm{MW}$ wind or aggregated RES is put into operation, and the energy storage capacity is used, even the $450 \mathrm{MW}$ generator \# 2 can be withdrawn from operation. We also see that the most appropriate source of renewable energy is the wind. In cases of the same installed capacity, the effectiveness of the wind energy in the region is much greater than the solar one.

So, the UC problem solving in case of Kazakhstan allows to conclude that in a dispersed power system with RES, it is possible to cover the shortage of power generation by increasing the share of RES and ensure sustainable development of the energy system in the region with minimizing the impact on the environment.

\section{Conclusions}

1. In all cases of simulation, the problem of UC was solved for the dispersed power system with RES in the western part of the Kazakhstan's power system.

2. It is possible to introduce new renewable energy capacities instead of traditional energy sources to cover the electricity deficit in the region, if there is a reserve of power on the traditional sources of generation, which remains in the power system. The capacity reserve and the characteristics of the generators at existing stations allow this to be done. 
3. The most appropriate source of renewable energy is the wind. In cases of the same installed capacity, the effectiveness of the wind energy in the region is much greater than the solar one. However, if the task is to output certain generators at certain time periods, then the use of aggregated generation from RES makes it possible to do this in a larger number of cases.

4. If the current load profile remains unchanged and $250 \mathrm{MW}$ wind or aggregated RES is put into operation and the energy storage capacity is used, even the 450 MW generator \# 2 can be withdrawn from operation.

5. Because of the characteristics of the power facilities not every part of the real dispersed power system can be considered as a microgrid.

6. The use of a power storage facility, the power calculated according to the proposed method, in practically all cases will make the work of a part of the power system autonomous.

\section{References}

[1] Saravanan B., Sikrid S.D., Kothari P. A solution to the unit commitment problem - a review. "Front. Energy", 7(2), 2013, pp. 223-236.

[2] Fossati J.P., Unit commitment and economic dispatch in micro grids, 2012. [online] [15.07.2017.] Available at:

http://www.um.edu.uy/docs/7_unit_commitment_and_economic_dispatch_in_micro_grids.pdf

[3] Murillo-S'anchez C. E., Zimmerman R. D., Anderson C. L., Thomas R. J., Secure Planning and Operations of Systems with Stochastic Sources, Energy Storage and Active Demand, "Smart Grid", IEEE Transactions on, vol. 4, no. 4, pp. 2220-2229, 2013. [online] [20.07.2017.] Available at: http://dx.doi.org/10.1109/TSG.2013.2281001 .

[4] Zimmerman R. D., Murillo-S'anchez C. E., Matpower. Optimal Scheduling Tool MOST 1.0 User's Manual, Power Systems Engineering Research Center (PSerc), 2016.

[5] Bytyrbekov I., Legislation in the field of renewable energy in Kazakhstan, GRATA, 2015. [online] [5.07.2017.] Available at: http://online.zakon.kz/Document/?doc_id $=31647811 \#$ pos $=1 ;-163$.

[6] MAEK departments. [online] [22.07.2017.] Available at: http://www.maek.kz/opredpriyatii/podrazdeleniya.

[7] Lee H.T., Chen S.H., Kang H.Y. A Study of Generalized Reduced Gradient Method with Different Search Directions, Department of Industrial Engineering and Management National Chin-Yi Institute of Technology, Taichung, Taiwan, Department of Industrial Engineering and Management Hsiou-ping Institute of Technology Taichung, Taiwan, 2004.

[8] KEGOC, National Dispatch Center of the System Operator. [online] [16.07.2017.] Available at:http://www.kegoc.kz/ru/o-kompanii/nacionalnaya-energosistema/ndc-so.

[9] Zimmerman R. D., Murillo-Sanchez C. E., Matpower Optimal Scheduling Tool MOST 1.0 User's Manual, Power Systems Engineering Research Center (PSerc), 2016.

[10] United Nations, Department of Economic and Social Affairs, World population prospects, the 2015 revision. [online] [11.01.2016.] Available at: https://esa.un.org/unpd/wpp/Download/Standard/Population/

[11] Energy Research Institute of The Russian Academy of Science, Forecast of the development of the energy sector of the world and Russia until 2040. [online] [11.01.2016.] Available at: https://www.eriras.ru/data/772/rus.

[12] Eurasian Economic Union. [online] [11.01.2016.] Available at: http://www.eaeunion.org/?lang = en\#about .

[13] Plaschinsky G. Eurasian Integration: Does Lukashenko Have a Choice? "Belarus Digest", 2014. [online] [12.01.2016.] Available at: https://belarusdigest.com/story/eurasian-integration-doeslukashenka-have-a-choice/?print $=$ print.

[14] Gulnur R., Anar R., Ulpan P. In Kazakhstan is faced with problems of electric power generation, "Analysts of the Agency on Investment Profitability Research. Business Kazakhstan", no.1 (298) 2012.

[15] A record figure reached power generation in Kazakhstan. [online] [13.01.2016.] Available at:http://www.zakon. kz/kazakhstan/4477173-rekordnojj-cifry-dostiglo-proizvodstvo.html.

[16] Central Dispatch Administration of Fuel and Energy Complex (GP "CDU TEK"). [online] [13.01.2016.] Available at: http://www.cdu.ru/files/CountryEnergy.pdf . 
[17] Netherlands - trading partners, "Explorer-Observer", no. 16-17. [online] [13.03.2016.] Available at: http://www.rau.su/observer/N16-17_94/16-17_17.htm

[18] Blog “All Energy". [online] [13.03.2016.] Available at: http://energomir.blogspot.com/2011/02/blog-post14.html

[19] Renewable energy in Kazkhstan, „KAZENERGY Magazin”, no.2-3, 2011. [online] [14.07.2017.] Available at: http://www.kazenergy.com/ru/2012-06-20-08-42-46/2012-06-20-13-01-53/ 53292011-07-29-17-55-58.html. 